\title{
An Adaptive Neuro-Fuzzy Inference System in Assessment of Technical Losses in Distribution Networks
}

\author{
Dragan Mlakić ${ }^{1}$, Srete Nikolovski ${ }^{2}$, Goran Knežević ${ }^{2}$ \\ ${ }^{1}$ Electric power company HZ-HB Inc. Mostar, Novi Travnik, Bosnia and Herzegovina \\ ${ }^{2}$ Department of Power Engineering, Faculty of Electrical Engineering, Osijek, Croatia
}

\begin{abstract}
Article Info
Article history:

Received Dec 10, 2015

Revised Feb 17, 2016

Accepted Feb 27, 2016

Keyword:

Adaptive neuro-fuzzy inference system Artificial intelligence

Lv distribution network

Remote meter reading

Technical losses

ABSTRACT

The losses in distribution networks have always been key elements in predicting investment, planning work, evaluating the efficiency and effectiveness of a network. This paper elaborates on the use of fuzzy logic systems in analyzing the data from a particular substation area predicting losses in the low voltage network. The data collected from the field were obtained from the Automatic Meter Reading (AMR) and Automatic Meter Management (AMM) systems. The AMR system is fully implemented in EPHZHB and integrated within the network infrastructure at secondary level substations $35 / 10 \mathrm{kV}$ and $10(20) / 0.4 \mathrm{kV}$. The AMM system is partially implemented in the areas of electrical energy consumers; precisely, in accounting meters. Daily information gathered from these systems is of great value for the calculation of technical and non-technical losses. Fuzzy logic in combination with the Artificial Neural Networks implemented via the Adaptive Neuro-Fuzzy Inference System (ANFIS) is used. Finally, FIS Sugeno, FIS Mamdani and ANFIS are compared with the measured data from smart meters and presented with their errors and graphs.
\end{abstract}

Copyright (C) 2016 Institute of Advanced Engineering and Science. All rights reserved.

\section{Corresponding Author:}

Srete Nikolovski,

Department of Power Engineering,

Faculty of Electrical Engineering, Josip Juraj Strossmayer University of Osijek,

K. Trpimira 2B, 31000 Osijek, Croatia.

Email: srete.nikolovski@etfos.hr

\section{INTRODUCTION}

Understanding of losses in an electricity network has always been essential due to losses directly resulting in the increase of an electricity price and indirectly energy efficiency [1]-[2]. Electricity losses occur in transformers, power lines, loads, reactors, capacitors and other network components [3]-[4]. For their assessment, either analytical computation or measurement methods are used [5]. Analytical computing assumes the knowledge of the equivalent scheme for various network elements; their physical properties and temporal changes of electrical quantities (currents, voltages) in current facilities, while measuring methods require measuring equipment, its installation (calibration, configuration) and regular reading [6]-[7]. In order to correctly predict the losses for future facilities within a distribution network, it is necessary to use both methods and their individual advantages. As with any approximation, ambiguities and uncertainties are possible; hence, errors may occur. However, ANFIS has been used in many engineering applications and especially in distribution and smart networks for modelling electricity demand [8]-[9], fault diagnosis [10] and fault location [11]. Very few papers deal with distribution losses estimation using ANFIS [12]. In this paper, fuzzy logic will be used in order to implement ANFIS for computation of losses in a low voltage distribution network. 


\section{LOSSES IN LV DISTRIBUTION NETWORK}

From the perspective of a network operator, losses are inevitable costs of the transmission of electrical energy through a distribution network causing additional loads in the power system. Generally, the term losses mean the difference between the amount of electrical energy that has entered into the distribution system and the measured amount of electrical energy which is delivered to customers. Losses can be categorized as technical and non-technical losses [1]. Technical losses in the components of the power system can be categorized as voltage-dependent losses and current-dependent losses. The latter are the results of the flow of current through the components of the power system and depend on the level of network usage, i.e. on the amount of transferred energy or the previous current. Voltage-dependent losses, which are constantly present in the network, are the results of the maintenance of the electricity system in a constant state of operational readiness to supply customers with electricity [2]. These include losses in transformer cores, dialectical losses of cables and capacitor banks. Also, technical losses depend on the length and cross section of the cables. Non-technical losses are otherwise known as commercial losses since their costs are socialized instead of directly charging network operators and suppliers [4],[5]. Unauthorized consumption of electricity refers to the unauthorized intervention of the meters and illegal connections. It is very difficult to establish the exact amount of such losses since most of them are probably undetected. Unmeasured consumption is usually associated with public lighting. The calculation procedure can often be inaccurate due to: measurement errors, collection and processing of data readings, which are related to the rest of nontechnical losses. A calculation method depends on the availability of measured data. In most countries, technical losses are calculated "ex-post" by the voltage levels [5],[7]. At voltage levels, where each measurement site has a continuous measurement, losses are calculated hourly based on the obtained readings. In medium and low voltage networks, the majority of measurement points are equipped with conventional measuring devices that are periodically read. In such cases, technical losses in power lines and transformers can be calculated by using various mathematical methods. It used to be commercially used; however, it has not been used since the appearance of digital smart meters.

\section{AUTOMATIC METER READING AND ADVANCE METER MANAGEMENT SYSTEM}

Prior to the AMR and AMM systems, various complex methods of approximation of losses in distribution networks were used. Nowadays, calculating is based on raw data with voltage levels that are taken into account in the calculation of losses. The AMR and AMM systems are constantly active and adaptable to end-users. A very important characteristic of these two systems is continuity in the activities of reading and their withdrawal from a database. Depending on the needs of users, in this case the distribution of electrical energy, meters that are placed in the LV feeders can serve as readouts acquired in different timeintervals (minute, hour, day). For example, the consumption in $\mathrm{kWh}$ for a period, which may not be less than 15 minutes (with the parameters for the meter can go up to $1 \mathrm{~min}$.), which is sufficient to calculate the hourly losses on some part of the network, can be easily calculated. This paper does not take into account voltage levels above $0.4 \mathrm{kV}$ because of the complexity of fuzzy models. The data to be read every day in the AMR system are on a server located in the Distribution EP HZ-HB building in Mostar [13]. The data can be read out with a delay of 24 hours [13]. The data from the AMM system are on the same server under another domain so they are separated by functionality. The LV distribution area exemplified in this paper is covered from the substation to the end customers with smart meters for measuring electricity consumption. The data used in this paper are taken directly from the server, which reads the meters installed in the substation and the end customers without any modification of the data. The situation presented in this paper is illustrated in Figure 1. As can be seen, the energy flow from the substation to the end customers is complemented with inevitable technical losses of electrical energy. Therefore, if one invests in a new LV network or maintain the existing one, one needs to know the extent of these losses. 


\section{LV network}

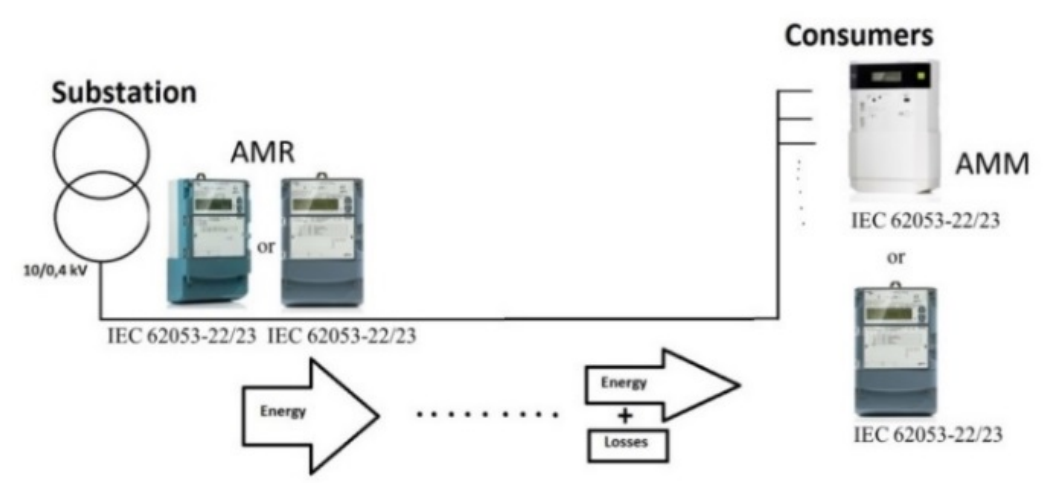

Figure 1. Graphical presentation of the Low Voltage network

The presented low voltage area consists of different conductors with the most present ones being 70 $\mathrm{mm}^{2}, 50 \mathrm{~mm}^{2}$ and $35 \mathrm{~mm}^{2}$. Each smart meter is installed on pole positions just in front of a consumer's object such as a house, workshop, etc. so other conductors smaller than $35 \mathrm{~mm}^{2}$ are connected after observed meters and they do not influence losses. A single line diagram for a distribution LV area, previously discussed, is presented in Figure 2.

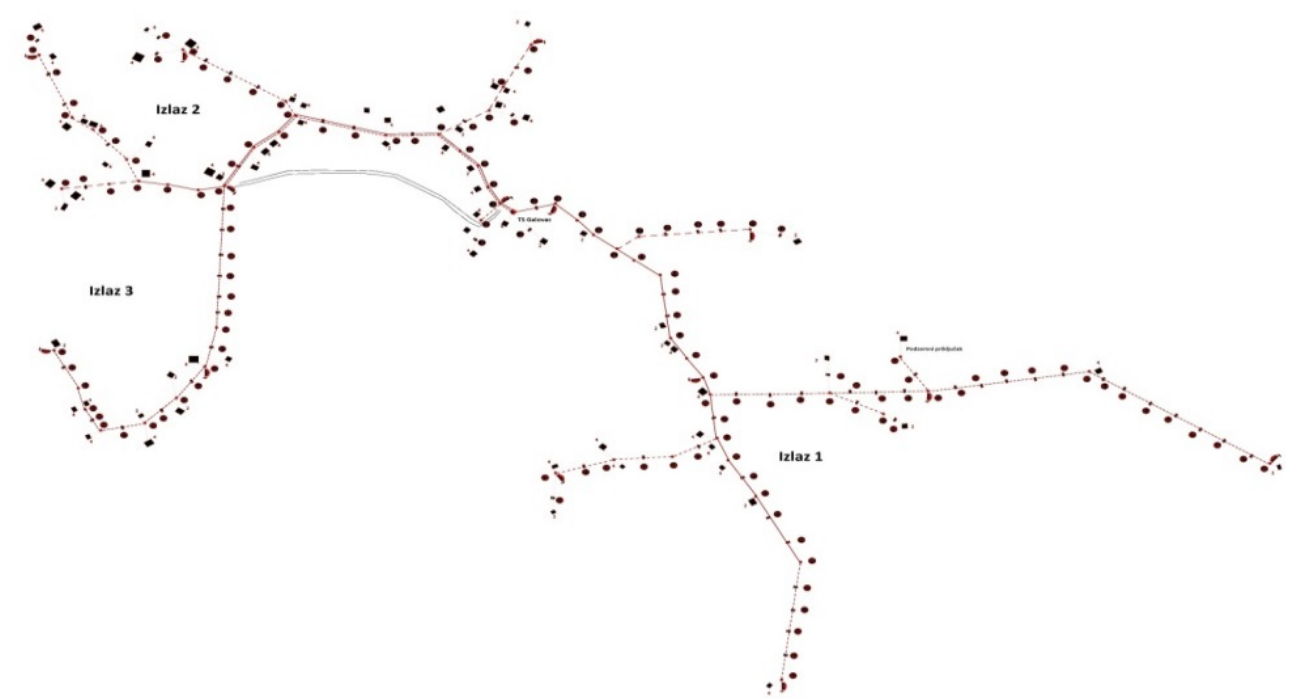

Figure 2. Single line diagram of the distribution LV network area

The counters with their respective characteristics used in the AMR and AMM systems are defined in the standards IEC 62053-22 and IEC 62053-23, as presented in Table 2. The table shows standards of losses in electrical energy measurement; therefore, this mistake needs to be taken into consideration during data acquiring. The meters used to measure the electricity consumption by customers are mostly 2009 generation; yet, they are gradually being replaced by a new generation. More detailed characteristics of the meters are not listed. Also, the communication technologies used for transmission of data from remote sites where the meters are installed are not elaborated on in this paper.

Table 2. Characteristics accuracy

\begin{tabular}{lr}
\hline Measuring accuracy Speed (rpm) \\
\hline Active energy according to IEC 62053-22 & Class 1/Class 2 \\
Reactive energy according to IEC 62053-23 & Class 2 \\
\hline
\end{tabular}




\section{FUZZY LOGIC}

Fuzzy logic is a concept much more natural than one might think. Recently, a number of different applications of fuzzy logic have significantly increased. Applications range from consumer products such as cameras, camcorders, washing machines and microwaves to control industrial processes, medical instrumentation, decision support systems and a choice of portfolio [8]. Fuzzy logic has two different meanings. However, in a broader sense, fuzzy logic is almost synonymous with the theory of fuzzy sets - the theory related to the class of objects with indistinct borders in which the membership is determined by a degree. Therefore, fuzzy logic in the narrow sense is a branch of the fuzzy logic. One relatively new approach to management is the application of a fuzzy controller. Fuzzy controllers are systems that actively regulate dynamic environment [9]. A prototypical example is a temperature controller on the inputs from a temperature sensor. It sets the engine temperature control devices to cool or warm environment [8],[9]. The general scheme of a fuzzy controller is illustrated in Figure 3.

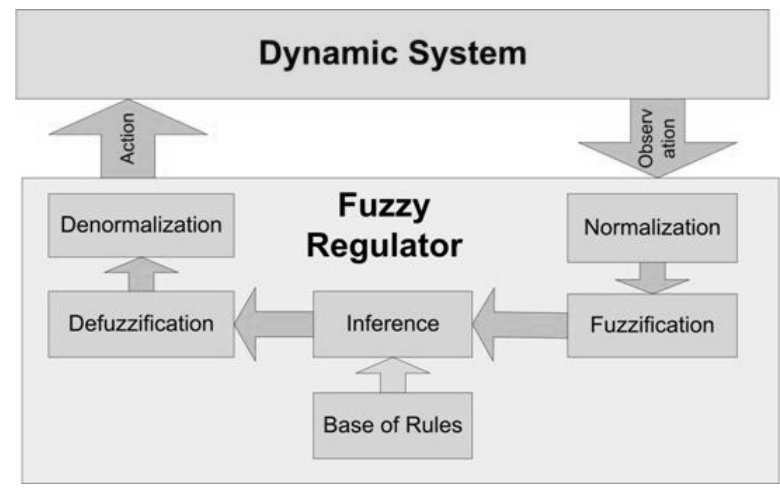

Figure 3. The general scheme of a fuzzy regulator

Fuzzy reasoning is the process of formulating a specific mapping input to an output using fuzzy logic. Mapping then provides a basis used to make a decision or to notice patterns. The program, which will be used to create a fuzzy system, is MatLab 2010a [14]. The part of MatLab to be used in this paper is a toolbox consisting of the ANFIS Editor which is used to train and test the fuzzy system by default rules GUIDE - a set of tools that are used to create interfaces and the M-file editor used to write programming codes. The two types of fuzzy reasoning can be carried out within the toolbox - Mamdani and Sugeno type. These two types of the reasoning system differ in the way they set out results. The process of fuzzy reasoning consists of five parts: fuzzification of input variables, the use of fuzzy operators (AND or OR), implications of the premise in consequence, the aggregation effect in accordance with the rules and defuzzification. ANFIS stands for the adaptive network fuzzy reasoning system or semantically equal, adaptive fuzzy reasoning neuro-system.

\subsection{Development of the ANFIS model}

The basic ANFIS model, as shown in Figure 4, is illustrated in five blocks of learning stages [11] [12]. This model is an example of the ANFIS development model for a power restoration plan that consists of two inputs and two membership functions.

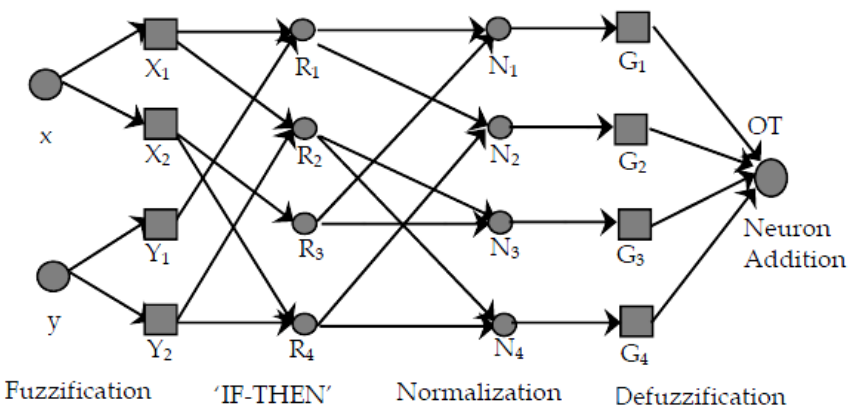

Figure 4. A basic ANFIS model with two input data and two MFs 
So, there are four fuzzy 'IF-THEN' rules to show the relationship between faults locations in ' $\mathrm{x}$, $\mathrm{y}$ ' coordinates. There are five stages of the ANFIS operational process that include fuzzification, 'IF-THEN' rules, normalization, defuzzification and neuron addition.

As illustrated in Figure 4, the fuzzification stage is located at the first stage of receiving the input signal. Its function is to convert the input signal to a fuzzy signal where the signal is yielded via the input side of the MF curve, defined by applying the following equations:

$$
\begin{aligned}
& X_{i}(x)=\frac{1}{\left.1+\frac{x^{2}-y_{i}}{a_{i}}\right]_{i}} \\
& Y_{i}(y)=\frac{1}{1+\frac{1}{g_{g}} 2^{2}}
\end{aligned}
$$

where, $\mathrm{Xi}(\mathrm{x})$ and $\mathrm{Yi}(\mathrm{y})$ are fuzzed values for each input data, while ai, bi and ci are the MF parameters for the respective representation of the middle, width and slope of the curve.

These parameters are varied accordingly to get a suitable curve in order to get a fuzzy signal. An output signal from the fuzzification stage becomes input to the stage of the 'IF-THEN' rule. In this stage, the fuzzy signal is gained by using the equation (3) to (6).

$$
\begin{aligned}
& R_{1}=X_{1}(x) * Y_{1}(y) \\
& R_{2}=X_{2}(x) * Y_{2}(y) \\
& R_{3}=X_{3}(x) * Y_{1}(y) \\
& R_{4}=X_{4}(x) * Y_{2}(y)
\end{aligned}
$$

R1, R2, R3 and R4 are real values for every 'IF-Then' rule.

Further, the output signal from the stage of 'IF-THEN' rule will be an input signal to the normalization stage. In this stage, every gained signal is divided to the total of a gained signal by the following equation:

$$
N_{i}=\frac{R_{i}}{R_{T}} \quad \mathrm{i}=1,2,3,4
$$

Where: $R_{T}=R_{1}+R_{2}+R_{3}+R_{4}$.

The next process is signal defuzzification in which the output signal from the normalization stage becomes an input signal to this defuzzification stage. In this stage, a normalized signal is gained again through a linear equation that is formed from the MF of the output signal as shown in the following equation

$$
G_{i}=N_{i}\left(p_{i} x+q_{i} y+r_{i}\right) \quad \mathrm{i}=1,2,3,4
$$

with pi, qi and ri are the MF parameters for the linear signal.

The last process in the ANFIS operation is called neuron addition in which all defuzzification signals Gi are added together as shown below:

$$
O T=\Sigma G_{i} \quad \mathrm{i}=1,2,3,4
$$

OT is a predicted value.

\section{ASSESSMENT OF TECHNICAL LOSSES}

The data to be used from the servers collected from the meters are the total consumption for a certain period of time of $0.4 \mathrm{kV}$ side of the substation and the total consumption of consumers connected to the substation for the same period [11],[12]. All consumption is expressed in $\mathrm{kWh}$. The goal is to create as precise ANFIS as it can be. Further, the smallest possible samples, in this case the sample of 15 minutes, are taken, as presented in Table 5. The period of learning, training and testing ANFIS work is three months. 
Table 5. The calculated loss for the samples of 15 minutes

\begin{tabular}{ccccc}
\hline Time & $\begin{array}{c}\text { Customer } \\
\text { consumption }(\mathrm{kWh})\end{array}$ & $\begin{array}{c}\text { Substation } \\
(\mathrm{kWh})\end{array}$ & $\begin{array}{c}\text { Losses } \\
(\mathrm{kWh})\end{array}$ \\
\hline $2015-1-100: 15$ & 8.85875 & 9.50 & 7.24 & 0.64125 \\
2015-1-1 00:30 & 8.40775 & 10.00 & 18.94 & 1.59225 \\
2015-1-1 00:45 & 8.18675 & 8.50 & 3.83 & 0.31325 \\
2015-1-1 01:00 & 8.17575 & 9.50 & 16.20 & 1.32425 \\
2015-1-1 01:00 & 8.17575 & 9.50 & 16.20 & 1.32425 \\
2015-1-1 01:15 & 8.14350 & 8.50 & 4.38 & 0.3565 \\
$2015-1-101: 30$ & 7.93850 & 8.50 & 7.07 & 0.5615 \\
$2015-1-101: 45$ & 7.91750 & 8.75 & 10.51 & 0.8325 \\
$2015-1-102: 00$ & 8.18350 & 8.25 & 0.81 & 0.0665 \\
$2015-1-102: 15$ & 6.84900 & 8.00 & 16.81 & 1.1510 \\
\hline
\end{tabular}

The losses in the electrical energy of the distribution system are the ratio of energy passed through the substation and energy that consumers have taken through their meters:

$$
G=\frac{E_{T}-E_{P}}{E_{T}} * 100 \%
$$

$\mathrm{G}$ - total losses expressed as a percentage (\%);

$\mathrm{E}_{\mathrm{T}}$ - energy that is recorded on the meters of the substation $(\mathrm{kWh})$;

$\mathrm{E}_{\mathrm{P}}$ - energy that is recorded on the meters of customers $(\mathrm{kWh})$.

The value $\mathrm{G}$ is calculated every 15 minutes during a day aiming at building a precise knowledge base ANFIS will be built upon. In order to reduce enormous amount of data, the decision is to take samples. For the purpose of this paper, 178 samples for training FIS and 80 samples for testing FIS are chosen. The best examples are those that come from different seasonal periods and different times of a day and night in order to properly model the low voltage network [12].

It is important to stress that the greater the number of samples, FIS will be more accurate; yet, calculation time is multiplied. When you calculate all the samples losses, it is necessary to define the transformer bay under review. Defining the transformer bay means making base characteristics data which includes cross sections ranging from the substation to the end customers, length of a conductor, type of material they are made of $(\mathrm{Cu}, \mathrm{Al})$, number of consumers, "dispersion" of consumers, temperature for each sample and relative humidity for each sample. Some of these characteristics are not so important for the loss calculation but may be considered as factors that affect the electric consumption and consequently the budget. Most of the characteristics can be found on the scheme showing the feeder (Figure 2) and weather conditions which can be found on the local weather conditions provider. It is necessary to calculate the formula (10) for 178 samples in order to determine the knowledge base. Among the recorded data, the columns such as the cross section of the cables $(70,50,35 \mathrm{~mm} 2)$, the air temperature $(\mathrm{T})$, humidity $(\mathrm{H})$, number of consumers $(\mathrm{CN})$, the substation (SS)-registered at the substation $\mathrm{kWh} \%$ - percentage of losses from SS to consumers will be inserted. Notice that there is no consumption in $\mathrm{kWh}$ for consumers. The reason is that this is already contained within the registration of energy within the substation and the percentage of losses to be calculated. So, data inputs are cross section of the cables, T, H, CN, and SS, while the output, losses in percentage (\%), comes from the FIS system [11],[12]. The information that is thrown away is the date and time. The reason is that the time is irrelevant considering the temperature and humidity characteristics because it can be determined that losses are unrelated to date but related to the conditions under which the LV network is working, which makes inputting data in MatLab Workspace much easier. After editing the data presentation, the table is made and afterwards inserted into MatLab Workspace. The observed substation areas have characteristics presented in Table 6. 
Table 6. Input data of transformer area

\begin{tabular}{|c|c|c|c|c|c|c|c|}
\hline $70 \mathrm{~mm}^{2}$ & $\begin{array}{c}\text { Cables } \\
50 \mathrm{~mm}^{2}\end{array}$ & $35 \mathrm{~mm}^{2}$ & $\begin{array}{c}\text { Temperature } \\
\text { oC }\end{array}$ & $\begin{array}{c}\text { Humidity } \\
\%\end{array}$ & $\begin{array}{l}\text { Customer } \\
\text { number }\end{array}$ & $\begin{array}{c}\text { Substation } \\
\text { kWh }\end{array}$ & $\begin{array}{c}\text { Losses } \\
\%\end{array}$ \\
\hline 6000 & 1200 & 2500 & -3 & 12 & 110 & 9.5 & 7.24 \\
\hline 6000 & 1200 & 2500 & -3 & 12 & 110 & 10 & 18.94 \\
\hline 6000 & 1200 & 2500 & -3 & 12 & 110 & 8.5 & 3.83 \\
\hline 6000 & 1200 & 2500 & -3 & 12 & 110 & 9.5 & 16.2 \\
\hline 6000 & 1200 & 2500 & -3 & 12 & 110 & 8.5 & 4.38 \\
\hline 6000 & 1200 & 2500 & -3 & 12 & 110 & 8.5 & 7.07 \\
\hline 6000 & 1200 & 2500 & -3 & 12 & 110 & 8.75 & 10.51 \\
\hline 6000 & 1200 & 2500 & -3 & 12 & 110 & 8.25 & 0.81 \\
\hline 6000 & 1200 & 2500 & -3 & 12 & 110 & 8 & 16.81 \\
\hline 6000 & 1200 & 2500 & -3 & 12 & 110 & 7.25 & 9.67 \\
\hline 6000 & 1200 & 2500 & -3 & 12 & 110 & 7.25 & 9.3 \\
\hline 6000 & 1200 & 2500 & -3 & 12 & 110 & 7 & 7.69 \\
\hline 6000 & 1200 & 2500 & -3 & 12 & 110 & 6.75 & 11.96 \\
\hline 6000 & 1200 & 2500 & -3 & 12 & 110 & 6.5 & 3.85 \\
\hline 6000 & 1200 & 2500 & -3 & 12 & 110 & 7.25 & 18.68 \\
\hline 6000 & 1200 & 2500 & -3 & 12 & 110 & 6.5 & 7.69 \\
\hline 6000 & 1200 & 2500 & -3 & 12 & 110 & 5.75 & -4.84 \\
\hline 6000 & 1200 & 2500 & -3 & 12 & 110 & 6.25 & 2.55 \\
\hline 6000 & 1200 & 2500 & -3 & 12 & 110 & 7 & 14.59 \\
\hline 6000 & 1200 & 2500 & -3 & 12 & 110 & 6.5 & 6.81 \\
\hline 6000 & 1200 & 2500 & -3 & 12 & 110 & 6.75 & 0.75 \\
\hline 6000 & 1200 & 2500 & -3 & 12 & 110 & 6.75 & 4.25 \\
\hline 6000 & 1200 & 2500 & -3 & 12 & 110 & 7.75 & 19.4 \\
\hline 6000 & 1200 & 2500 & -2 & 16 & 110 & 7 & 6.47 \\
\hline
\end{tabular}

Upon completion of sampling, the data need to be fed into MatLab where the ANFIS building is done. First, the data are translated so that the Data Importer recognizes and saves them as the knowledge base. It is crucial to clean the information of "dirt" that only brings confusion and unnecessary delays in the calculation of the fuzzy rules. In this example, the samples that have value "0" are bad because there was no consumption, i.e. the distribution network was out of the operation or the meter did not measure; therefore, the data are not valid. Hence, data processing needs to be done prior to the ANFIS training. In addition, before processing the data, "cleaning" of the table knowledge base, that pollute the knowledge base, needs to be done. Cleaning is done manually by finding values that are not good examples for the assessment and are possible errors in meter reading. It is necessary to go through the data table, look for values that are abnormal, like faults in the distribution network or switching of line breakers etc., and delete them from the specimen. When the base sample is ready for the ANFIS training, open the ANFIS Editor from the command line and import the data that are prepared for the training. Figure 5 shows the imported data when presented in the ANFIS Editor accompanied by the most of work on ANFIS, training, testing, checking, managing error and training epochs. After creating ANFIS, it is necessary to train FIS to successfully meet the criteria of accuracy. For testing purposes, the table created from the same data as the table to create FIS was used. The criterion of accuracy depends on the users who will use the above FIS system. The satisfactory level of an error depends on the knowledge base used to create FIS, the methods used for modeling and user sensitivity.

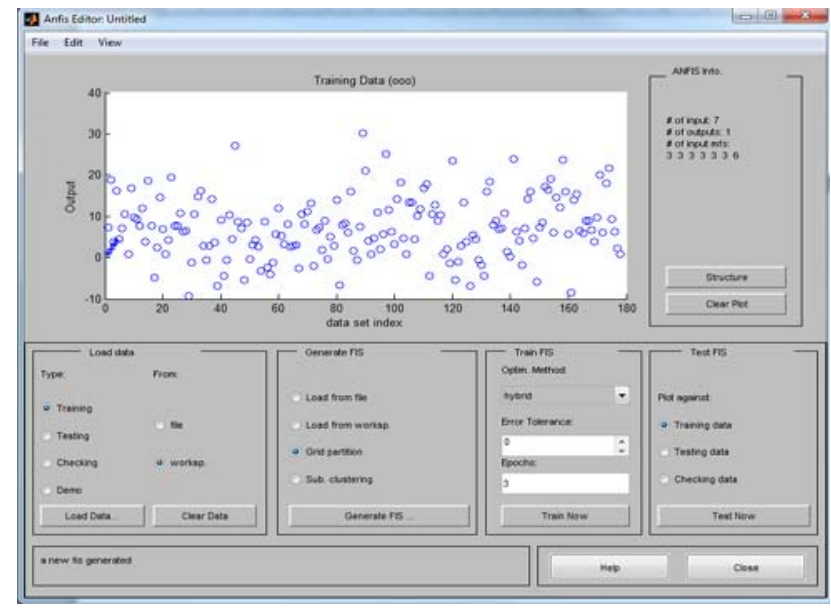

Figure 5. ANFIS Editor, which creates a fuzzy system that is based on the entered data 
In this case, three epochs are sufficient to train and will take a level of an error to $5 \%$. In the properties of FIS, the membership function data are presented. It is possible to manually change the type, scope and parameters of the function itself if the membership functions do not correspond to the level of sensitivity of the data that it represents. Figure 6 shows the ANFIS Model Rules generated from the imported data. Depending on the input data tuning and membership functions rules can be more or less generated. It is best to have more rules to cover most of input situations but it is impossible to cover them all, so continued development of ANFIS is of great importance.

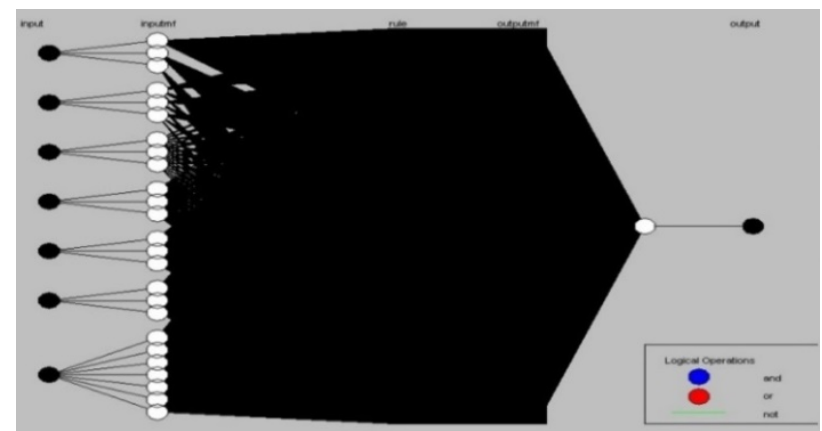

Figure 6. The structure of the created ANFIS model

Figure 6 demonstrates how the structure ANFIS model created FIS looks. Clearly, a lot of rules are used for 7 inputs and 1 output. Considering the information used for creating FIS, the possibilities of fuzzy logic are clear. The number of created "if-then" rules is 2,187 , which is not a lot if the number of the entered samples is considered. Figure 7 shows the membership functions for input no. 7, which is a registered flow through the substation. Now, test FIS is created due to the data which are loaded into the workspace. As can be seen in Figure 8, a standard error testing FIS is 29.1628. It is a great error from the perspective of the distribution system. The error of $30 \%$ poured into energy losses is significant. In order to reduce the error, introduction of more samples and taking samples from several different periods have to be done. As the number and quality of samples increase, FIS will be more accurate.

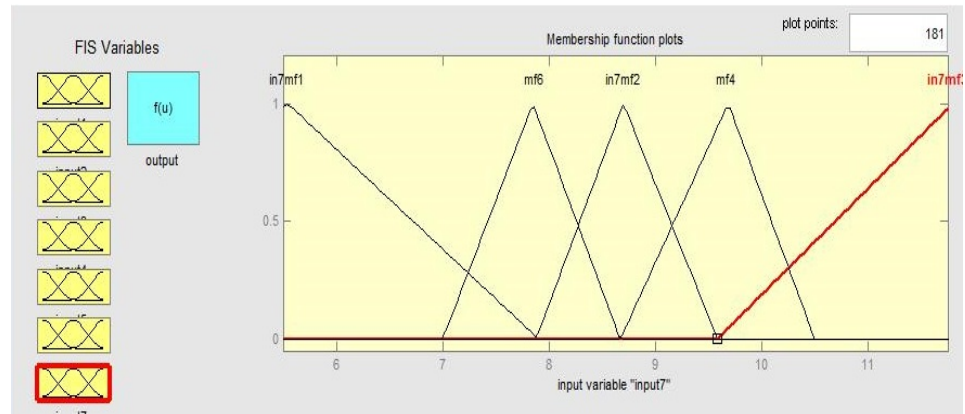

Figure 7. Membership function inputs for registered energy through the substation

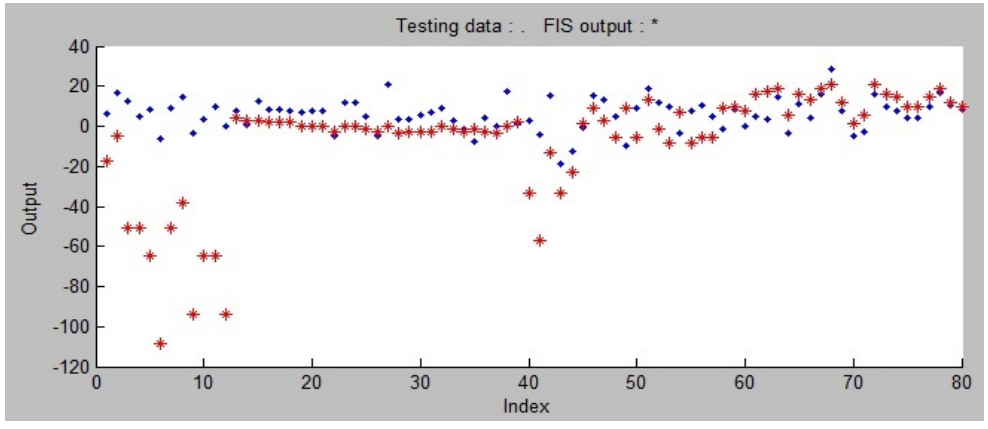

Figure 8 . The test results of the created FIS 
Creating FIS for the assessment of physical behavior is an evolving process; fuzzy logic is based on the knowledge base, which is improved with more experience. It is important to notice that this method can only calculate technical losses for a certain LV feeder for a certain period of time under certain weather, climate and technical requirements. Even though losses may include a non-technical aspect, the method in this case can clearly separate the technical from non-technical losses. After performing the simulation for a certain period, the results obtained from the simulation are compared with the measured actual values. In the event that deviates more than a specified allowable threshold (in this case, to consider the error counters, current transformers, the application itself, which has a clear mistake), there is a presence of non-technical losses in the LV network with a +/- error that was mentioned. Creating FIS Sugeno and FIS Mamdani is very similar to creating ANFIS except when creating MF. [2],[11]-[13]. In ANFIS Editor, in MatLab, new FIS is created and finally Sugeno or Mamdani are to be chosen. The difference is in the output function. Mamdani provides the choice between several output functions such as trimf, gaussmf, zmf, etc. and Sugeno gives us two choices - constant or linear. For FIS Mamdani, three MFs are chosen, namely gaussmf, trimf and gaussmf as shown in Figure 9. For FIS Sugeno, three MFs are chosen and it will be a linear type as shown in Figure 10. MFs of seven inputs are the same in both of these reasoning systems. Temperature, humidity and registered $\mathrm{kWh}$ in the substation influence the output MF the most. The reason for this is in the types of conductors installed in the LV distribution network and the number of consumers of electrical energy being the same most of the time, so it does not influence losses during time on a different level. The system is integrated with the application using such interface.

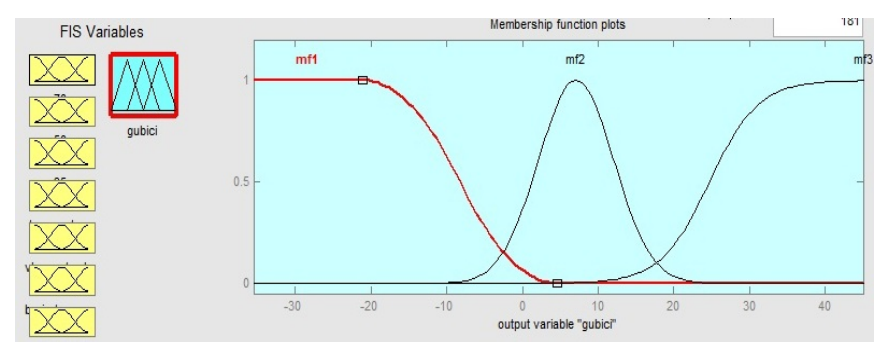

Figure 9. Membership functions of the Mamdani output

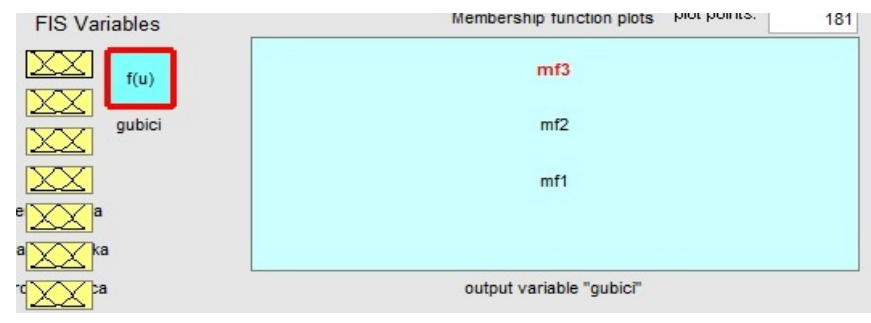

Figure 10. Membership functions of the Sugeno output

\section{COMPARISON OF THE RESULTS}

When the application with FIS Mamdani, FIS Sugeno and ANFIS are integrated into the executable file, the comparison of the measured data from the field (smart meters) with the calculated ones from the application can be done. For example, 80 measured specimen and 80 calculated values from the application are taken and presented in Figure 11 and 12. There is a clear difference in accuracy between three methods. Errors $-1.29 \%$ for ANFIS, $-2.56 \%$ for FIS Mamdani and $-1.09 \%$ for FIS Sugeno are recorded according to the generated results. FIS Sugeno has the lowest recorded error. In addition, the trend of FIS Sugeno is mostly neutral of specimen time that is not promising for longer period of approximation. Further analysis shows that ANFIS has the best trend according to the measured values from AMR but has bad results in the beginning. FIS Mamdani has the steadiest trend but the highest error. The deviation of the errors decreases for longer specimen. The reason is that the longer specimen, the better period results. In that way, it cannot be ignored, especially when the assessment declares the course of expenses inside the investment or maintenance of the distribution network. Errors of $-1.29 \%,-2.56 \%$ and $-1.09 \%$ are great starting points for further research on the FIS system. The fuzzy-based approximation method is one of the easiest and fastest 
growing methods for the assessment. In conclusion, we can suggest a combination of several methods in order to provide better overall results than the ones obtained. Taking more samples of this application and combining them will provide results that are more accurate. Also, the voting mechanism for all 3-inference methods can bring a better trend.

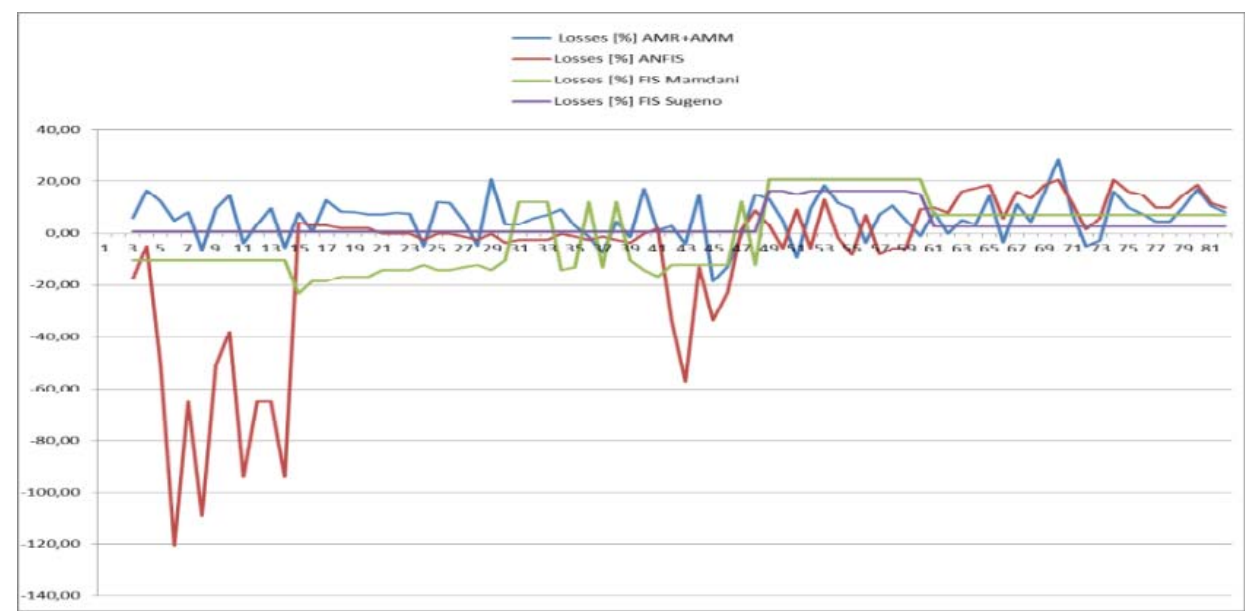

Figure 12. Graphic presentation of measured and calculated losses in the LV distribution network

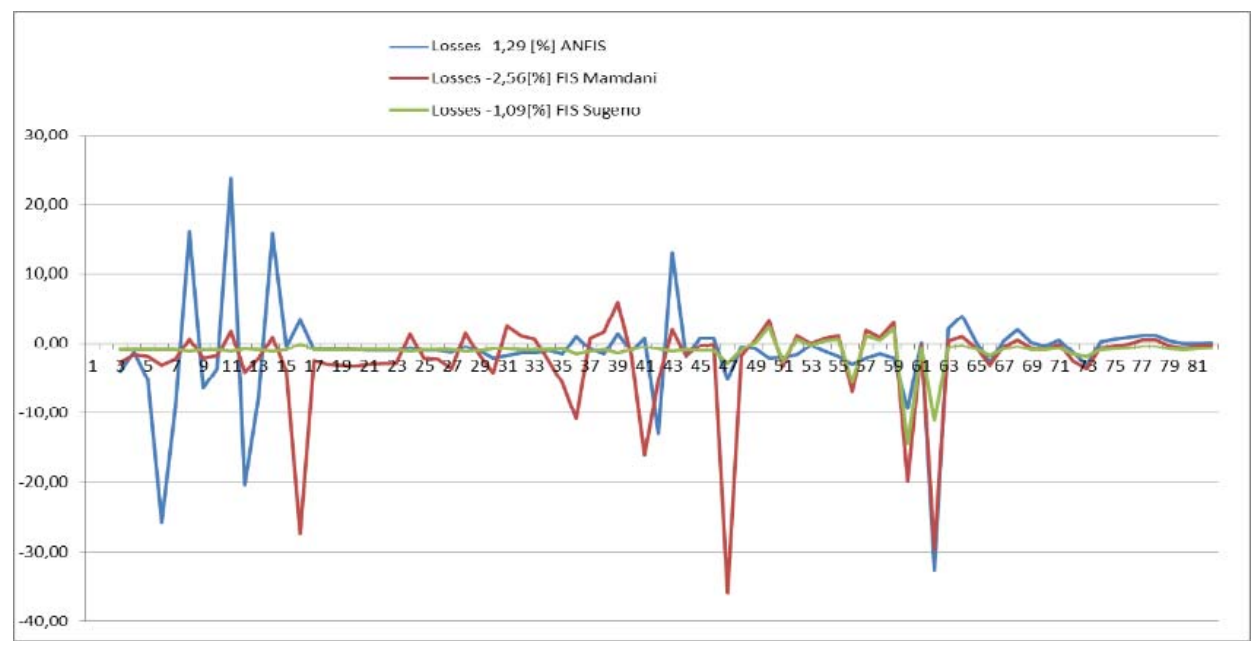

Figure 13. The error between the measured and calculated losses in the LV distribution network

\section{CONCLUSION}

The paper describes the advantages of using fuzzy logic to approximate losses on the low voltage electricity distribution network. The method accuracy depends on the specific practical examples to be used as references because measurement data are used to create knowledge bases, which are further used to derive membership functions. In long-term approximation, the best method is ANFIS because as specimen grows in number, it becomes close to real measured values, which lowers down the error percentage. In comparison to Sugeno and Mamdani, ANFIS is the easiest to upgrade from training data. Its application is not limited solely to the low voltage network but can be applied on the transmission network. By enriching the base elements of the distribution network with new features and putting the network in new weather conditions, the distribution network losses can be well estimated and computed with ANFIS.

\section{ACKNOWLEDGEMENTS}

We would like to thank the Department for Distribution of Electrical Energy HZ-HB Inc. Mostar for allowing us to use the Smart Meter grid infrastructure. 


\section{REFERENCES}

[1] A. Onen, et al., "Time-varying cost of loss evaluation in distribution networks using market marginal price," International Journal of Electrical Power \& Energy Systems, 2014.

[2] G. Grigoras, "Estimation of Power/Energy Losses in Electric Distribution Systems based on an Efficient Method," TELKOMNIKA Indonesian Journal of Electrical Engineering, vol/issue: 11(9), pp. 4855-4860, 2013.

[3] M. Sulaima, et al., "A DNR Using Evolutionary PSO for Power loss reduction," Journal of Telecommunication, Electronic and Computer Engineering, 2013.

[4] S. Myint, "Network Reconfiguration for Loss Reduction and Voltage Profile Improvement of 110-Bus Radial Distribution System Using Exhaustive Search Techniques," International Journal of Electrical and Computer Engineering (IJECE), vol/issue: 5(4), pp. 788-797, 2015.

[5] M. Afridi, et al., "GSM Based Smart Distribution System," International Journal of Electrical and Computer Engineering (IJECE), vol/issue: 2(5), pp. 589-596, 2012.

[6] A. Rossoni, et al., "Hybrid Formulation for Technical And Non-Technical Losses Estimation And Identification In Distribution Networks: Application In A Brazilian Power System," 23rd International Conference on Electricity Distribution, Lyon, 15-18 June 2015, pp. 1365.

[7] R. Ferreyra and P. Paoletich, "Model For Losses Calculation And Breakdown In Distribution Systems," CIRED 2001, Conference Publication, vol. 482, 2001.

[8] A. B. Nath, "A neuro-fuzzy approach for modelling electricity demand in Victoria," Applied Soft Computing, vol. 1, pp. 127-138, 2001.

[9] A. Draidi and D. Labed, “A Neuro-fuzzy Approach for Predicting Load Peak Profile," IJECE, vol/issue: 5(6), 2015.

[10] R. Hussain and Fauzi, "Fault Diagnosis in Power Distribution Network Using Adaptive Neuro-Fuzzy Inference System, Fuzzy Inference System - Theory and Applications,” Dr. Mohammad Fazle Azeem (Ed.), ISBN: 978-95351-0525-1, InTech.

[11] J. Florez and G. Caicedo, "Fault Location in Power Distribution Systems using ANFIS Nets and Current Patterns," IEEE PES Transmission and Distribution Conference and Exposition, Latin America, Venezuela, 2006.

[12] P. Sekar, et al., "A Novel Method for Estimation of HT and LT Feeder Losses in Distribution System," Fifteenth National Power Systems Conference, IIT Bombay, December 2008.

[13] MATLAB 7.10.0 (R2010a), software.

[14] "System of Automatic Meter Reading from Distribution system operator EP HZ-HB d.d. Mostar".

\section{BIOGRAPHIES OF AUTHORS}
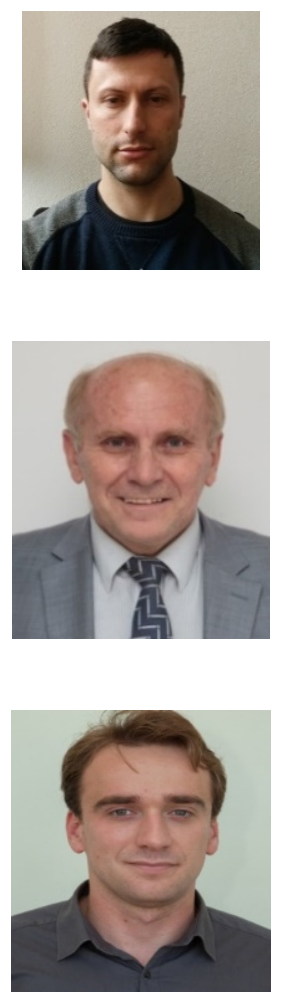

Dragan Mlakić, MSc (IEEE M 2015) was born in Travnik on June 15, 1981. He obtained his BSc degree (2007) and MSc degree (2013) in Electrical Engineering at the Faculty of Electrical Engineering, University of Sarajevo, Bosnia and Herzegovina. He currently works as an engineer in the Electric power company HZ-HB Inc. Mostar, Novi Travnik and as Senior Assistant at the Department of Software Engineering at the Faculty of Information Technology, University of Vitez, Bosnia and Herzegovina. His main interests are artificial intelligence, expert systems, renewable energy, system modeling and smart grids.

Srete Nikolovski, PhD (IEEE M'1995, SM'2005) was born in Belgrade on October 1, 1954. He obtained his BSc degree (1978) and MSc degree (1989) in Electrical Engineering at the Faculty of Electrical Engineering, University of Belgrade and his $\mathrm{PhD}$ degree (1993) at the Faculty of Electrical and Computing Engineering, University of Zagreb, Croatia. He is a Full Professor at the Department of Power Engineering at the Faculty of Electrical Engineering, University of Osijek, Croatia. His main interests are power system protection, power system modeling, simulation and reliability. He has published 180 academic papers in journals and international conferences proceedings. He is IEEE Senior member of Reliability Society and PES Society.

Goran Knežević, PhD, was born on September 1, 1984. He obtained his diploma degree in 2007 and $\mathrm{PhD}$ degree in 2013 from the Faculty of Electrical Engineering, J.J. Strossmayer University of Osijek, Croatia. He currently works as an Assistant Professor at the Department of Power Engineering at the Faculty of Electrical Engineering Osijek. His topics of research include electricity markets simulation, energy markets integration, power system economics and cost/benefit assessment, optimization of power system operation and power system analysis. 